\title{
Analytic Theory of the Rayleigh-Taylor Instability in a Uniform Density Plasma-Filled Ion Diode
}

Thomas W. Hussey, Steven S. Payne

Prepared by

Sandia National Laboratories

Albuquerque, New Mexico 87185 and Livermore, California 94550

for the United States Department of Energy

under Contract DE-AC04-76DP00789

When printing a copy of any digitized SAND Report, you are required to update the markings to current standards. 
Issued by Sandia National Laboratories, operated for the United States Department of Energy by Sandia Corporation.

NOTICE: This report was prepared as an account of work sponsored by an agency of the United States Government. Neither the United States Government nor any agency thereof, nor any of their employees, nor any of their ment nor any agency thereof, nor any of their employees, nor any of their contractors, subcontractors, or their employees, makes any warranty, ex-
press or implied, or assumes any legal liability or responsibility for the press or implied, or assumes any legal liability or responsibility for the
accuracy, completeness, or usefulness of any information, apparatus, product, or process disclosed, or represents that its use would not infringe privately owned rights. Reference herein to any specific commercial product, process, or service by trade name, trademark, manufacturer, or otherwise, does not necessarily constitute or imply its endorsement, recommendation, favoring by the United States Government, any agency thereof or any of or favoring by the United States Grovernment, any agency thereof or any of their contractors or subcontractors. The views and opinions expressed herein do not necessarily state or reflect those of the United States Government, ny agency thereof or any of their contractors or subcontractors.

Printed in the United States of America Available from

National Technical Information Service

U.S. Department of Commerce

5285 Port Royal Road

Springfield, VA 22161

NTIS price codes

Printed copy: A02

Microfiche copy: A01 


\title{
Analytic Theory of the Rayleigh-Taylor Instability
}

\section{in a Uniform Density Plasma-Filled Ion Diode}

\author{
Thomas W. Hussey and Steven S. Payne \\ Radiation and Hydrodynamics Theory \\ Division 1261
}

\begin{abstract}
The $\vec{J} \times \vec{B}$ forces associated with the surface current of a plasma-filled ion diode will accelerate this plasma fill toward the anode surface. It is well known that such a configuration with a high $\dot{I}$ is susceptible to the hydromagnetic Rayleigh-Taylor instability in certain geometries. A number of ion diode plasma sources have been proposed, most of which have a falling density going away from the wall. A somewhat more unstable case, however, is that of uniform density. In this report we attempt to establish an upper limit on this effect with a simple analytic model in which a uniform-density plasma is accelerated by the magnetic field anticipated in a PBFA-II diode. We estimate the number of linear e-foldings experienced by an unstable surface as well as the most damaging wavelength initial perturbation. This model, which accounts approximately for stabilization due to field diffusion, suggests that even with a uniform fill, densities in excess of a few $10^{15}$ are probably not damaged by the instability. In addition, even lower densities might be tolerated if perturbations near the most damaging wavelength can be kept very small.
\end{abstract}




\section{Introduction}

As current flows along the surface of the plasma fill in an fon diode, the $\vec{J} \times \vec{B}$ forces accelerate that plasma toward the anode. ${ }^{1}$ sinoe this process Is potentially susceptible to the hydromagnetic Rayleigh-Taylor instablilty ${ }^{2}$, we were asked to quantify the amplification of initial perturbations that would ocour due to this effect with realistic ion diode conditions. A variety of such conditions have been proposed, the most unstable of which involves a uniform density, singly-ionized lithium plasma extending same distance out fram a wall. We have chosen this density profile for a worst case study. Furthermore, we have assumed this accelerated plasma to be semi-infinite in extent. In reality, such a plasma may extend only a few millimeters out from the surface, and growth will stop when the moving plasma actually strikes the wall. Thus, the results in this memorandum should not be regarded as a condemation of anp particular diode designs, but merely as a warning that such problems exist and as a suggestion of some parameters that should be avoided. The intent was and is to use HAM, a two-dimensional (2-D), single-fluid MHD code ${ }^{3}$, which would include the effects of such processes as snowplow stabilization ${ }^{4}$ and field diffusion on nonlinear instability growth. ${ }^{5}$ Before performing such calculations, however, we felt we ought to examine our worst case assessment of the problem analytically, in order to understand, if not to limit, the parameter space involved. To this end we analytically estimate the linear growth rate and integrate over the time during which the interface is unstable to abtain the number of linear e-foldings. We use this as a figure of merit as to whether the growth will significantly amplify any initial perturbation that might be present. In this memorandum we give results from this analytic study. 
II. The Basic Model

There are a variety of plasma sources under consideration for PBFA II that will lead to a variety of different density profiles. We won't discuss those sources here; instead, we consider only what we belleve to be the case most susceptible to the hydromagnetic Rayleigh-Taylor instability, a uniform plasma being pushed back by a time-dependent magnetic field given by

$$
.18 \mathrm{MG}(\mathrm{t} / 10 \mathrm{~ns})^{0.75} \quad \mathrm{t} \leq 10 \mathrm{~ns}
$$

Since diffuston will be a relatively more effective smoothing mechanism with a constant magnetic field than with a risting field, we only consider the first 10 ns here. Furthermore, since we ultimately intend to compare to HAM calculations, we use the following units

$$
\begin{aligned}
& t \quad \text { - microsecond } \\
& \text { l - centimeter } \\
& m \quad-\text { gram/am } \\
& \text { B - megagauss } \\
& P \quad-\text { megabar } \\
& \eta \quad-\text { milliahm - centimeter }
\end{aligned}
$$

Thus, we have

$$
B=5.692 t^{0.75}
$$


which gives for magnetio pressure

$$
P=B^{2} / 8 \pi=1.289 t^{1.5}
$$

The equation of motion for an interface of area, A, total mass, $M(t)$, and velocity, $v(t)$, is given by

$$
P A=\frac{d}{d t}(M(t) v(t)) \rightarrow P=\frac{d}{d t}(m(t) v(t))
$$

where lower case $\mathrm{m}$ is just mass per unit area. This is easily integrated from zero to t to give

$$
\begin{aligned}
& \int_{0}^{t} d t^{\prime} P=\int_{0}^{t} d t^{\prime} \frac{d}{d t^{\prime}}(m v) \\
& m(t) v(t)=.5157 t^{2.5}
\end{aligned}
$$

This may be evaluated in the "pure snowplow" limit where all the material through which an interface sweeps sticks to that interface in an infinttesimally thin layer. In this limit we have

$$
m=x p, \quad v=\frac{d x}{d t},
$$

where we take $x(t=0)=0$. From Eqs. 4 and 5 we have

$$
m v=x p \frac{d x}{d t}=\frac{\rho}{2} \frac{d x^{2}}{d t}=.5157 t^{2.5}
$$

which is again integrated over $t$ to give 


$$
\begin{aligned}
& x^{2}=.2047 t^{3.5} / \rho, \\
& x=.5428 t^{1.75 / \rho^{0.5}}, \\
& v=.9499 t^{.75 / \rho^{0.5}}, \\
& a=d v / d t=.7124 t^{-0.25 / \rho^{0.5}} .
\end{aligned}
$$

One dimensional (1-D) MED calculations have been performed with TITAN of the system described above for a density of $10^{-7}$ (1.e., an ion density of about $10^{16}$ ), and the velocity of the outer edge of the plasma is compared to Eq 7 in Figure 1. We note that the agreement is quite poor at early time when field penetration dominates. Nevertheless, after a few nanoseconds the TITAN velocity parallels the analytic result, indicating comparable acceleration at that time.

With Eqs. 6-8 we are now able to estimate the Rayletgh-Taylor (R-T) instability growth rate, $Y$, from the approximate formula ${ }^{7}$,

$$
\gamma=\left(\frac{2 \pi a}{\lambda+\lambda}\right)^{0.5}
$$

where $\lambda$ is wavelength. This is similar to the usual expression for linear growth except for $\lambda_{\mathrm{dg}}$, which is a measure of the density gradient scale length. Note that for $\lambda$ " $\lambda_{\mathrm{dg}}$ (1.e., a step function interface) this reduces to the familiar expression for linear R-T growth, $\gamma=\sqrt{k a}$. We find from the form of the above equation that $\gamma$ is largest for shortest wavelength. With $\lambda$ short compared to the diffusion length, $\lambda_{d}$, however, we anticipate that growth will be inhibited, particularly when the nonlinear 
stage is reached. Thus, in order to estimate a maximum value for $\gamma$, we evaluate the above for $\lambda=\lambda_{\mathrm{d}}=\lambda_{\mathrm{d} g}$

$$
\gamma=\left(\pi a / \lambda_{d}\right)^{0.5}
$$

where we recognize that diffuston determines density gradient scale length. Diffusion length may be approximated by ${ }^{8}$

$$
\lambda_{\mathrm{d}}=(\eta t / \pi)^{0.5}
$$

where $\eta$ is in milliohm-an and $t$ is in microseconds. The usual expression for $\eta$ is

$$
\eta=4 \pi v / \omega_{\mathrm{pe}}^{2}
$$

where $v$ is an electron momentum transfer collision frequency and $\omega_{\text {pe }}$ is the electron plasma frequency

$$
\omega_{p e}=5.64 \times 10^{4} n_{e}^{0.5} \mathrm{sec}^{-1}=4.376 \times 10^{16}(\mathrm{Z} / \mathrm{A})^{0.5} \rho^{0.5} \mathrm{sec}^{-1} .
$$

Anomolous resistivity is expected ${ }^{9}$ under these conditions. Then, the anomolous collision frequency is approximately equal to the ion plasma frequency where

$$
\omega_{p 1}=\left(Z m_{e} / m_{1}\right)^{0.5} \omega_{p e}=2.334 \times 10^{-2}(Z / A)^{0.5} \omega_{p e},
$$

which gives with Eq. 12 


$$
\begin{aligned}
& \eta=.2033(\mathrm{Z} / \mathrm{A})^{0.5} \omega_{\mathrm{pe}}^{-1}=6.702 \times 10^{-18} \rho^{-0.5} \mathrm{sec}, \\
& \eta=6.032 \times 10^{-3} \rho^{-0.5} \mathrm{mt} 111 \mathrm{hhm}-\mathrm{cm},
\end{aligned}
$$

and with Eq. 11

$$
\lambda_{d}=4.382 \times 10^{-2} \rho^{-0.25} t^{0.5}
$$

Thts implies that $\lambda_{d}$, which we take to be the most unstable wavelength for $R-T$ growth, is increasing as $\sqrt{ } t$. It is tabulated for a variety of densities at $t=10 \mathrm{~ns}$ in Table $I$.

The fact that $\lambda_{d}$ is not constant in $t$ implies that one must use Eq. 9 to evaluate $\gamma$, rather than $\mathrm{Eq}$. 10. To evaluate the number of Iinear $e-$ foldings, $n_{e f}^{0}$, we integrate the growth rate over time

$$
n_{e f}^{0}=\int_{0}^{t_{f}} \gamma d t=\int_{0}^{t_{f}} d t\left(\frac{2 \pi a}{\lambda+\lambda_{d}(t)}\right)^{0.5} .
$$

Since we want to celculate the case with maximum $n_{\text {ef }}^{0}$ we choose the smallest wavelength possible consistent with $\lambda, \lambda_{d}$. With $\lambda_{d}(t)$ growing monotonically in time, this minimum wavelength is simply $\lambda_{d}\left(t_{f}\right)$. Taking this into acoount and substituting Eq. 8 and 11 into the above gives

$$
\begin{aligned}
& n_{e f}^{0}=1.011 \rho^{-1 / 8} s_{0}^{t_{f}} t^{-1 / 8}\left(t_{f}^{1 / 2}+t^{1 / 2}\right)^{-1 / 2} d t, \\
& n_{e f}^{0}=1.011 \rho^{-1 / 8} x\left(t_{f}\right),
\end{aligned}
$$


where Figure 2 gives results of evaluating $x(t)$ mmerically. Table 1 gives $n_{\text {ef }}^{0}$ evaluated at $10 \mathrm{~ns}(x(10 \mathrm{~ns})=.051)$ as a function of $10 \mathrm{n}$ number density where we assume singly lonized lithium. Also included are diffusion length, velocity and distance traveled, all evaluated at $10 \mathrm{~ns}$. We note that, even at an ion density as high as $10^{17}$, we obtain more than an order of magnitude amplification of an appropriate scale length initial perturbation.

\section{Quasi-Two-Dimensional Interface Calculations}

The above is a simplified treatment of a quite complex process and it is important to keep in mind the approximations used. One such approximation is the fact that snowplow stabilization ${ }^{3}$ is only included to the extent that it reduces the acceleration profile. Full 2-D calculations will include the fact that this effect preferentially slows the "bubble" portion of the nonlinear R-T instability ${ }^{4}$ as 1 t penetrates the plasma. We were able to use the zero-dimensional interface code, ZORKa $D^{10}$, which does account for this effect, to determine that, despite stabilization, significant instability growth is achieved. Because of mumerical problems intrinsic to this model it is usually difficult to carry instability calculations well into the nonlinear phase with such a code. Nevertheless, Figure 3 shows results from a calculation with a simusoldal $\pm 5 \%$ density perturbation having a $2.5 \mathrm{~mm}$ wavelength superimposed on a $10^{16}$ ion density. We have plotted $\left(v_{\mathbf{S}}-v_{b}\right) / v_{0}$ where $v_{\mathbf{S}}$ is spike (highest density) velocity, $v_{b}$ is bubble (lowest density) velocity, and $v_{0}$ is mean velocity. From Eq. 7 we recall that velocity is proportional to $p^{-0.5}$. Thus, we would expect ( $v_{S}$ $\left.-v_{b}\right) / v_{0}$ to be constant at appraximately 05 if the motion of the spike and bubble regions were uncoupled. The figure shows, however, that this ratio starts at the proper value, but then grows as mass moves from the lower 
density region to the higher density region. Thus, even though the Interface calculation cannot be run long enough to see significant accumulation of mass in the spike region, we find the cocurrence of exponential growth.

IV. Effect of Magnetic Field Penetration

Another important effect that will only be treated approximately here is magnetic field diffusion. This effect has already been included approximately in that the diffusion length, $\lambda_{d}$, evaluated at $t_{f}$ (taken to be 10 ns in Table 1), was used to determine the wavelength of the most damaging mode. Nevertheless, a comparison of $\mathrm{Eq}$. 6, whtch shows $\mathrm{x}$ increasing as $t^{1.75}$, to $\mathrm{Eq}$. 14, which shows $\lambda_{d}$ increasing as $t^{0.5}$, indicates that at some early time diffuston will dominate advection (see Figure 1). During this time it is quite reasonable to suppose that there will be no apprectable R-T growth. This suggests the posstbility of cutting off the integral over the growth rate at early time to acoount for this. In order to find the time, $t_{\text {eq, }}$ at which diffusion and advection are equal, we set $\mathrm{Eq}$. 6 equal to $\mathrm{Eq}$. 14 and solve for 'teq'

$$
\begin{aligned}
& .5428 t_{e q}^{1.75} / \rho^{0.5}=4.382 \times 10^{-2} \rho^{-0.25} t_{e q}^{0.5}, \\
& t_{e q}=.1335 \rho^{0.2},
\end{aligned}
$$

which is evaluated in Table 1. Note that such a transition from diffusion dominated to advection-dominated flow is illustrated in Figure 1. (For this example at $10^{16} \mathrm{~cm}^{-3}$ density, $t_{e q}=5 \mathrm{~ns}$, compared with the slope change at 
4 ns.) We use this result to agatn find the mumber of Iinear e-foldings, this time accounting for dffusion by cutting off the integral at early time

$$
\begin{aligned}
& n_{e f}=\int_{t}^{t_{e q}} \lambda d t=\int_{t}^{t_{e q}} d t\left(\frac{2 \pi a}{\lambda+\lambda_{d}(t)}\right)^{0.5}, \\
& n_{e f}=\int_{0}^{t_{f}}\left(\frac{2 \pi a}{\lambda+\lambda_{d}(t)}\right)^{0.5}-\int_{0}^{t_{e q}}\left(\frac{2 \pi a}{\lambda+\lambda_{d}(t)}\right)^{0.5} .
\end{aligned}
$$

Again, following the reasoning leading to Eq. 15, we find

$$
n_{e f}=1.011 \rho^{-1 / 8}\left(x\left(t_{f}\right)-x\left(t_{e q}\right)\right)
$$

where $\chi(t)$ is evaluated in Figure 2 and $n_{\text {ef }}$ is evaluated in Table 1.

Comparing $n_{e f}$ to $n_{e f}^{0}$ we find that diffusion effects are greatest at highest density. Thus, $n_{e f}$ is a stronger function of density than $n_{e f}^{0}$. If we rather arbitrarily consider an order of magnitude amplification of an Initial perturbation of the most unstable wavelength to be our threshold of acceptable instability growth, we find that densities below a few times $10^{15}$ are unacceptable. Note that, in order to use Table 1 to estimate effects of the R-T instability, there are three quantities to consider: the mumber of e-foldings, the most damaging wavelength, and the amplitude of perturbations at or near that wavelength. Large perturbations of much shorter wavelength will actually be smoothed by field diffusion and represent very little prablem. Large perturbations of wavelength much longer than the most unstable one will experience growth, but with a considerably reduced growth rate (see Eq. 9). 
V. Effect of Finite Ion Dwell Time

All of the above analysis has assumed that the plasma is essentially flutd-like. The fact is, however, that the relatively low density and high electric field present ensure that partiale effects will play some role despite anomolous collistonal1ty. In particular, reflection of ions by the advancing magnetic piston means that ions, if they experience no collisions, will only spend a finite time in the acoelerating region, which has a thickness of $\lambda_{d}$. This instantaneous "dwell" time, $t_{d}$, is approximated by 9

$$
\begin{aligned}
& t_{d}=4 \lambda_{d} / v \\
& t_{d}=.1845 \rho^{0.25} t^{-0.25} .
\end{aligned}
$$

Thus, $t_{d}$ starts very large and decreases in time. Since instability growth requires that lons remain at the unstable interface (see ref. 2 for a general discussion of the Inear R-T instability), a measure of whether this problem can be neglected is whether a dwell time exceeds the time for instability growth. An approximate (though somewhat arbitrary) way to estimate this, which accounts for the fact that $t_{d}$ is time dependent, is to define a new dwell time, $t_{d}^{\prime}$, such that

$$
\int_{t_{e q}}^{t_{d}^{\prime}} \frac{d t}{t_{d}(t)}=1
$$

where we have cut the integral off at $t$ ' $t_{\text {eq. }}$, when little instability growth is expected. This is easily integrated to give

$$
t_{d}^{1.25}=.2306 \rho^{0.25}+t_{e q}^{1.25}
$$


which with $\mathrm{Eq}$. 16 gives

$$
\begin{aligned}
& t_{d}^{\prime 1.25}=.2962 \rho^{0.25}, \\
& t_{d}^{\prime}=.3767 \rho^{0.2} .
\end{aligned}
$$

In order for lons to remain at the accelerating layer during the time scale of interest

$$
\begin{aligned}
& 10 \mathrm{~ns}<t_{d}^{\prime}, \quad .01<.3767 \rho^{0.2}, \\
& \rho>1.318 \times 10^{-8} \mathrm{~g} / \mathrm{cm}^{3} .
\end{aligned}
$$

Thus, for densities less than the above $\left(n_{1}<1.318 \times 10^{15}\right)$ we can expect finite dwell time effects to modify fluid-model predictions for R-T Instability growth. Since it is at precisely these low densities that such an instability can be expected to have the greatest effect, any theoretical program to assess such problems in detall would require 2-D hybrid (or particle) code calculations.

\section{Other Approximations}

If Ion emission removes mass from the accelerated layer at the fieldplasma interface at a rate comparable to the accretion rate, then a stabilizing effect analogous to "fire polishing"ll in ICF targets can be expected. In order to assess at what density, if any, this effect would be important, we must first relate in (recall that $m$ is mass per unit area) to a current density 
$1 \mathrm{~g} / \mathrm{usec- \textrm {cm } ^ { 2 }} \rightarrow 6.02 \times 10^{23} / \mathrm{A}$ 1ons $/ \mu \mathrm{sec}-\mathrm{cm}^{2}$

$\rightarrow \quad 1.608 \times 10^{10} \mathrm{Amps} / \mathrm{cm}^{2}$,

where we have taken $A=6$. Going back to $\mathrm{Bq}$. 16 we find that for densities less than $2.538 \times 10^{-6} 8 / \mathrm{cm}^{3}$ the transition from being diffusion dominated to being advection-dominated occurs before $10 \mathrm{~ns}$. Since realistic systems would have lower density than this, we must consider the in resulting from both. At first diffusive field penetration dominates,

$$
\begin{aligned}
\dot{m}_{d}=\rho \frac{d}{d t} \lambda_{d} & =2.191 \times 10^{-2} \rho^{0.75} t^{-0.5} \mathrm{~g} / u s e c-\mathrm{cm}^{2} \\
& \rightarrow 3.522 \times 10^{8} \rho^{0.75} t^{-0.5} \mathrm{Amss} / \mathrm{cm}^{2} .
\end{aligned}
$$

After $t=t_{e q}$ advective motion dominates

$$
\begin{aligned}
\dot{\mathrm{m}}_{\mathrm{a}}=\rho \mathrm{v} & =.9499 \rho^{0.5} t^{0.75} \mathrm{~g} / \mathrm{sec}-\mathrm{cm}^{2} \\
& \rightarrow 1.527 \times 10^{10} \rho^{0.5} \mathrm{t}^{0.75} \mathrm{Amps} / \mathrm{cm}^{2} .
\end{aligned}
$$

We first note that $\mathrm{m}_{\mathrm{d}}$ decreases with increasing $t$ so that the corresponding current density must exceed Eq 20 at $t=t_{e q}$ if it is to exceed it at all. In other words, for fire polishing to occur we must satisfy the condition

$$
J \sim 1.527 \times 10^{10} \rho^{0.5} t^{0.75} \text {, }
$$

which for $t=10 \mathrm{~ns}$ (1.e., when $J$ is largest) gives 


$$
J \sim 4.83 \times 10^{8} \rho^{0.5} \mathrm{Amps} / \mathrm{cm}^{2} .
$$

For an Ion density of $10^{15}$, therefore, we requitre a $J$ of the order of $4.83 \mathrm{x}$ $10^{4} \mathrm{Amps} / \mathrm{cm}^{2}$, compared with current densities of $0.1-1.0 \times 10^{4} \mathrm{Amps} / \mathrm{cm}^{2}$ typically extracted from ton diodes.

Another passible stabilizing mechanism is the effect of entrained B-z field on R-T growth. We have not attempted to include the back pressure due to this field in the pressure equation (Eq. 3), because we don't know how to assess diffusive leakage of field out of the compressed plasma analytically. Nevertheless, with only $5 \mathrm{~T}$ of field present both inside and outside the plasma we would expect little effect until the field-plasma interface has moved more than halfway to the wall.

\section{Conalusions}

In this memorandum we have used a very simple model for plasma dynamics in the presence of an intense magnetic field to assess the effects of Rayletgh-Taylor instability growth in plasma-filled ion diodes. The simplest and most pessimistio case of a uniform plasma density was considered and a projected magnetic field vs. time profile was used to get acceleration vs. time. This was then used to abtain the growth rate of the most unstable mode, taken to have a wavelength equal to a magnetic field diffusion length. We then integrated the growth rate, accounting for field diffusion by cutting off the integral at early time, to abtain the number of linear e-foldings. This cutoff was found to qualitatively reproduce the results from 1-D calculations. Therefore, we take the number of linear efoldings, evaluated as a function of plasma fill density in Table I, as our figure of merit for assessing the unstable response of this system to 
Inttial perturbations. We find from this process that noticeable (order of magnitude or more) amplification of an inttial perturbation is highly likely for densities less than a few times $10^{15}$. Thus, we can eliminate this problem elther by keepting the denstty suffictently high or by avolding perturbations at the damaging sale length. In addition, there are other factors suggesting that present designs may not be hurt by this effect. The Bolvaps density profile that increases as one approaches the wall will be less unstable, and, furthermore, the plasma is quite thin and will very likely stagnate against the wall well before $10 \mathrm{~ns}$. Nevertheless, this simple model 1llustrates that such a problem could exdst, and it presents an easily applied criterion for assessting R-T instabllity growth for certain alternative designs. 


\section{Table 1}

$n_{1}$

$p \quad \lambda_{d} \quad t_{\text {eq }} \quad n_{\text {ef }}^{0} \quad n_{\text {ef }} x(10 \mathrm{~ns}) \quad v(10 \mathrm{~ns})$

$10^{14}$

$10^{-9} \quad .778 \mathrm{~cm}$

$2.116 \mathrm{~ns}$

6.833

5.476

$5.43 \mathrm{~cm} 950 \frac{\mathrm{cm}}{\mu \mathrm{sec}}$

$3.16 \times 10^{14}$

$3.16 \times 10^{-9} \quad .584$

2.663

5.818

4.261

3.05

534

$10^{15}$

$$
10^{-8} \quad .438
$$

3.353

5.123

3.223

1.72

300.4

$3.16 \times 10^{15}$

$$
3.16 \times 10^{-8} \quad .329
$$

4.221

4.438

2.337

.966169.

$10^{16}$

$$
10^{-7} \quad .246
$$

5.315

3.843

1.578

$.543 \quad 95.0$

$3.16 \times 10^{16}$

$3.16 \times 10^{-7} \quad .185$

6.690

3.327

.827

$.305 \quad 53.4$

$10^{17}$

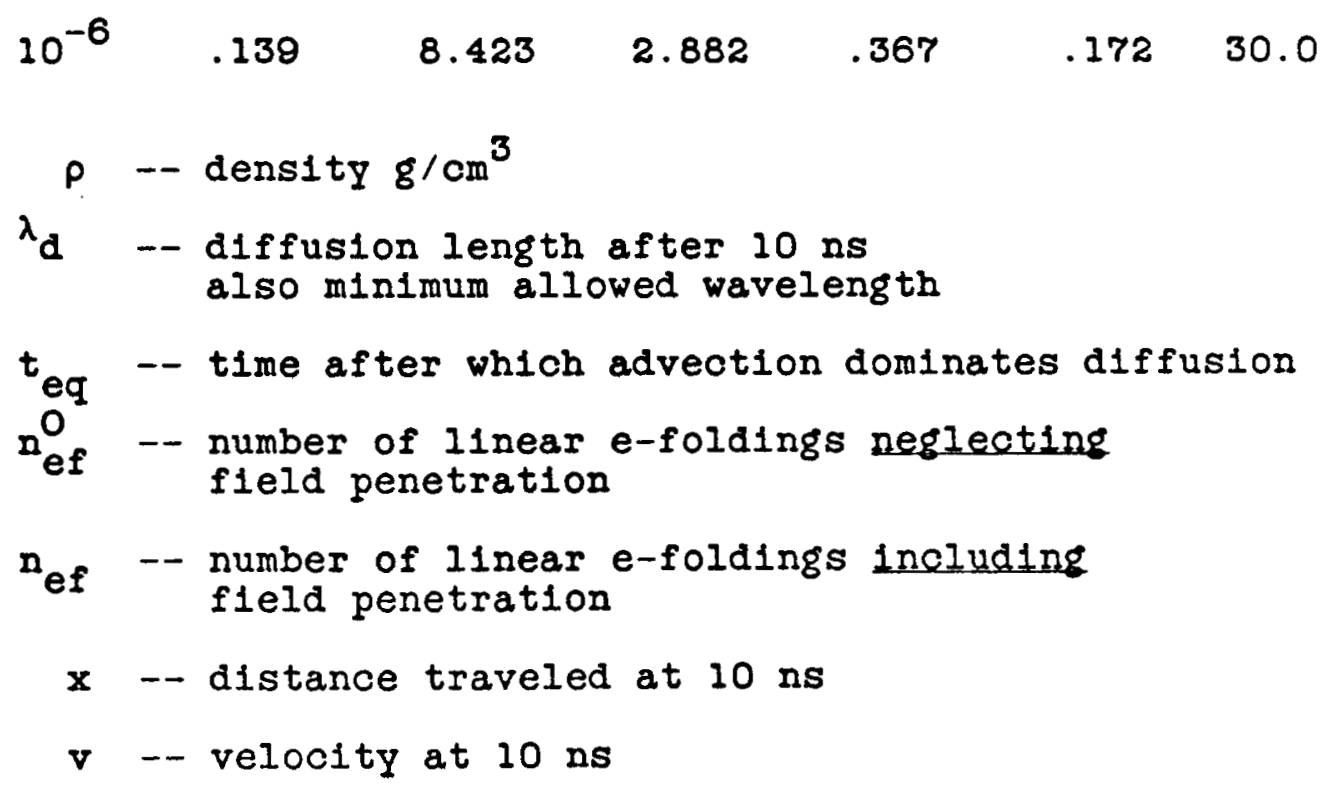




\section{COMPARISON TO TITAN CALCULATIONS}

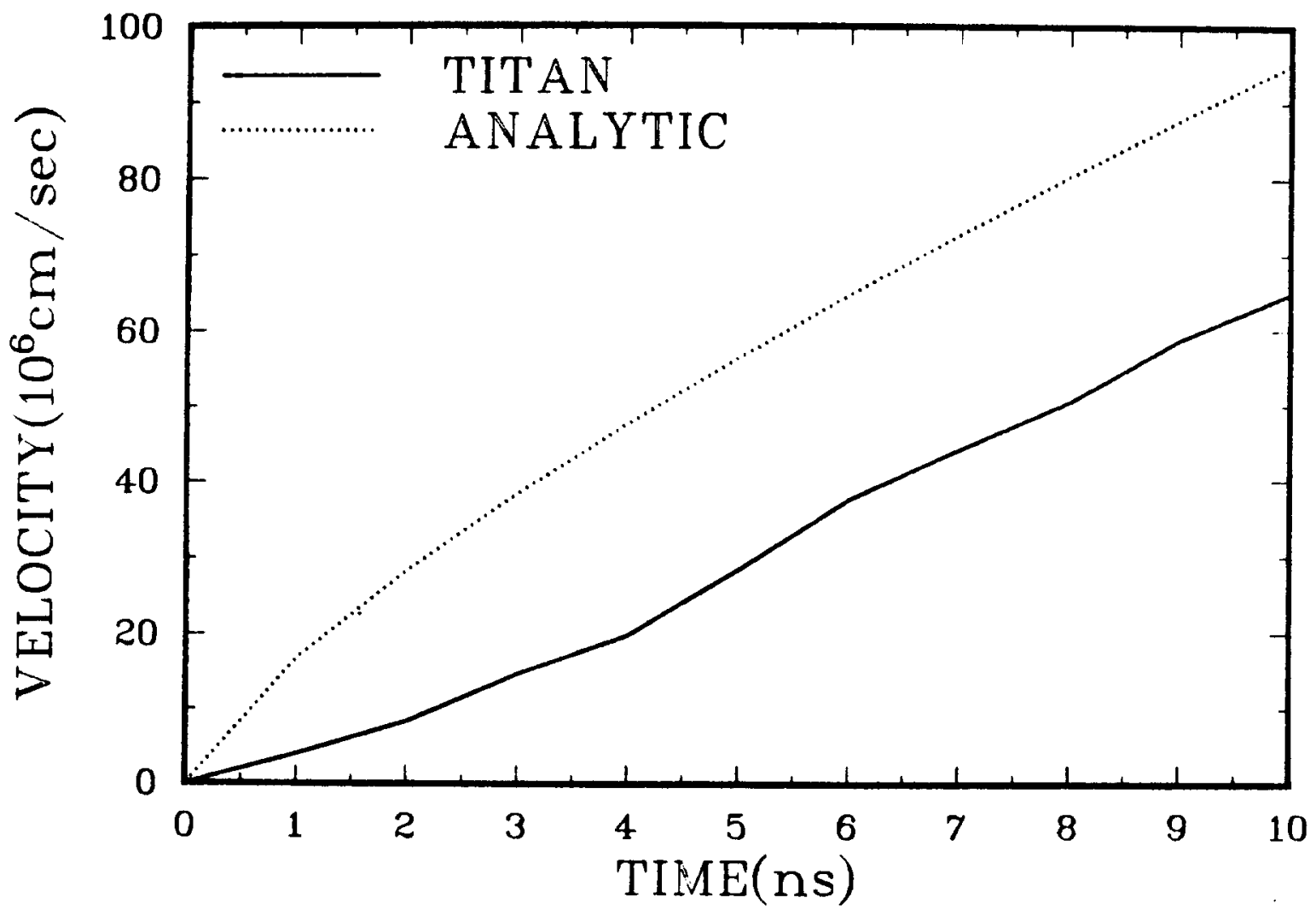

Figure 1. Compares the velocity from Equation 7 to that obtained from the comparable $1-D$ MHD calculation using TITAN for an ion density of $1 \times 10^{16} \mathrm{~cm}^{-3}$. 


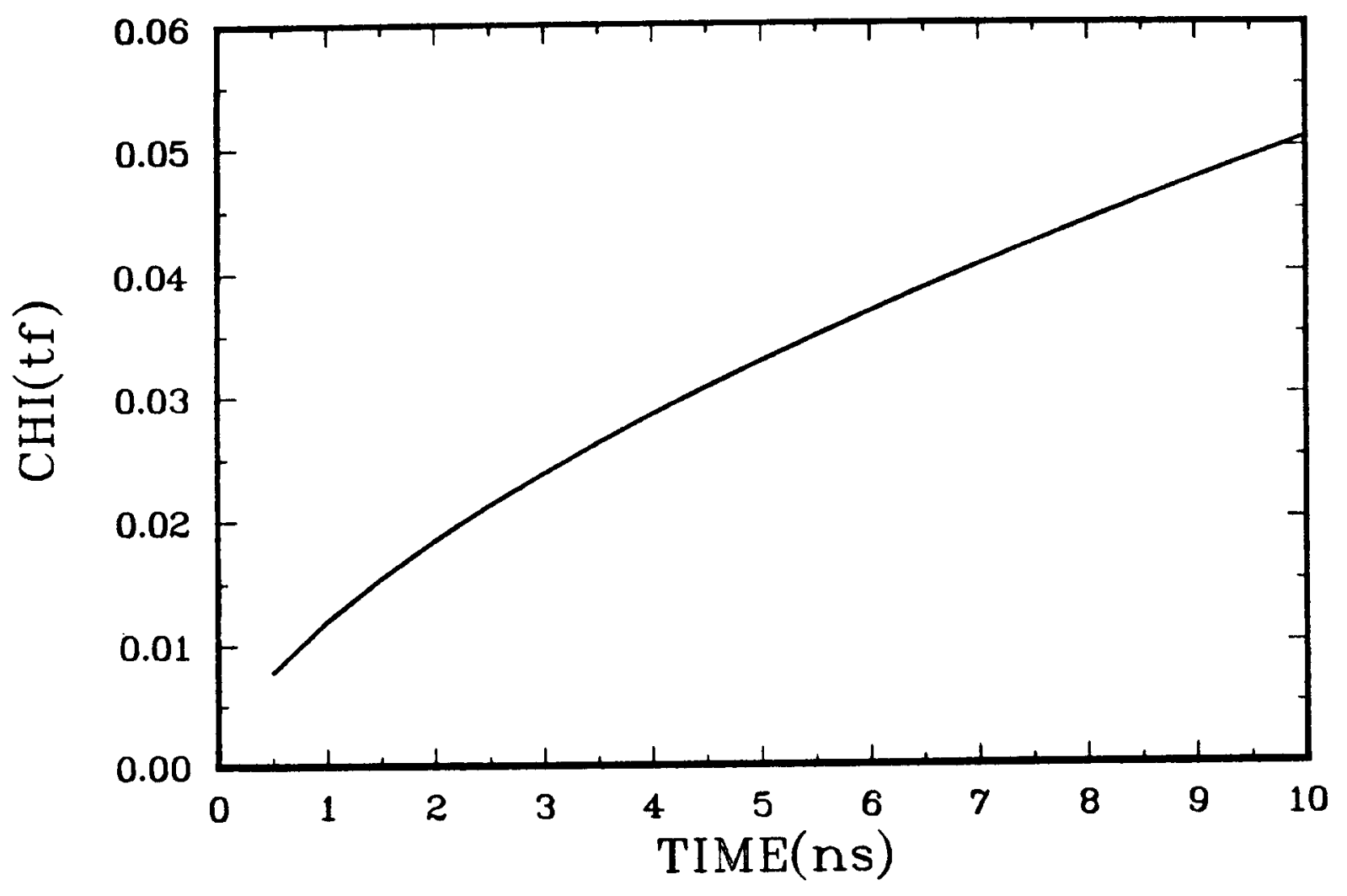

Figure 2. Evaluates the function $X(t)$ from Equation 15. 


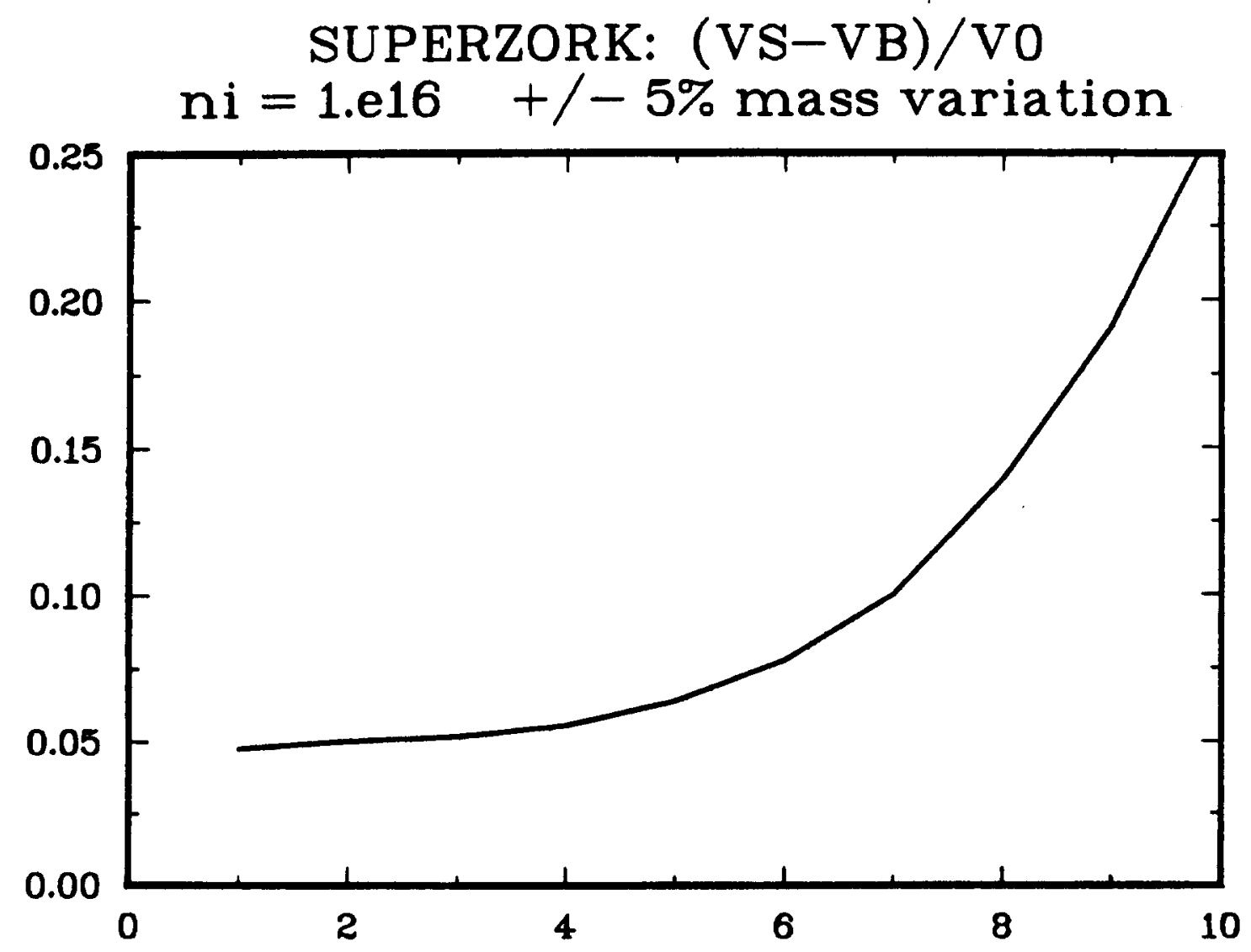

Figure 3. Shows instability growth from SUPERzORK. "Spike" velocity minus "bubble" velocity divided by mean velocity is plotted. 


\section{REIFERENTES}

1.) C. W. Mendel and G. S. Kills, J. Appl. Phys. 53, T265 (1982).

2.) S. Chandrasekhar, Hydrodynamte and Hydromagnetic Stability, (Oxford Univ. Press, Oxford, 1961).

3.) S. Maxon and J. Fddleman, Phys. Flutds 21, 10 (1978).

4.) T. W. Hussey, "Instabtlities in Cylindrioal Plasma Iiners Imploded by High Magnetic Fields," in Ultrahion Magnetic Fields. Physics. Techniques, and Applications, edited by V. M. Titov and G. A. Shvetsov, (Nauka, Moscow, 1984).

5.) T. W. Hussey, N. F. Roderick, and D. A. Kloc, J. Appl. PhYYs. 51, 1452 (1980).

6.) J. B. Chase, J. M. IeBlanc, and J. R. W1lson, Phys. Fluids 16, 1142 (1973).

7.) R. Lelevier, G. J. Lasher, and F. Bjorklund, Univ. of Calif. Report UCRL-4459, 1955.

8.) N. A. Krall and A. W. Trivelptece, Principles of Plasma Physics. (MoGraw-Hi11, New York, 1973).

9.) C. I. Olson, Lasers and Particle Beams 2, 255 (1984).

10.) T. W. HusseY, M. K. Matzen, and N. F. Roderick, J. Appl. Phys. 59, 2677 (1986).

11.) S. E. Bodner, Phys. Rev. Lett. 33, 761 (1974). 
SAND87-1120

Unlimited Distribution

UC-20g

Distribution:

$\begin{array}{llll}1200 & \text { J. P. Vandevender (5) } & 1263 & \text { J. N. O1sen } \\ 1241 & \text { J. R. Freeman } & 1263 & \text { K. W. Bieg } \\ 1241 & \text { R. S. Coats } & 1263 & \text { E. J. T. Burns } \\ 1241 & \text { B. M. Marder } & 1263 & \text { P. L. Dreike } \\ 1241 & \text { K. J. O'Brien } & 1263 & \text { J. Maenchen } \\ 1241 & \text { C. L. Olson } & 1263 & \text { R. E. Olson } \\ 1241 & \text { J. W. Poukey } & 1263 & \text { F. C. Perry } \\ 1241 & \text { D. B. Seide1 } & 1264 & \text { P. A. Miller } \\ 1241 & \text { J. S. Wagner } & 1264 & \text { C. W. Mendel } \\ 1244 & \text { R. A. Gerber } & 1264 & \text { L. P. Mix } \\ 1244 & \text { R. G. Adams } & 1264 & \text { C. Ruiz } \\ 1244 & \text { R. A. Hamil } & 1265 & \text { J. P. Quintenz } \\ 1244 & \text { E. L. Patterson } & 1265 & \text { M. Desjarlais } \\ 1244 & \text { G. C. Tisone } & 1265 & \text { W. A. Johnson } \\ 1244 & \text { J. R. Woodworth } & 1265 & \text { M. L. Kiefer } \\ 1260 & \text { D. L. Cook } & 1265 & \text { P. McAllister } \\ 1261 & \text { M. J. Clauser (10) } & 1265 & \text { T. A. Meh1horn } \\ 1261 & \text { G. O. Allshouse } & 1265 & \text { S. E. Rosenthal } \\ 1261 & \text { T. J. Burgess } & 1265 & \text { S. A. Slutz } \\ 1261 & \text { R. J. Dukart } & 1265 & \text { M. A. Sweeney } \\ 1261 & \text { T. W. Hussey (20) } & 1270 & \text { R. B. Miller } \\ 1261 & \text { C. J. MacCallum } & 3141 & \text { S. A. Landenberger } \\ 1261 & \text { E. J. McGuire } & 3151 & \text { W. L. Garner (3) } \\ 1261 & \text { S. S. Payne (5) } & 3154-1 & \text { DOE/TIC (28) } \\ 1261 & \text { I. R. Shokair } & 8024 & \text { Tech Library }\end{array}$

